研 究 速 報

\title{
群知能 $\mathrm{ACO}$ における刺激型女王アリ戦略の検討*
}

飯村伊智郎 $\dagger$. 伊藤登志也 $\ddagger$ 中山 茂

\section{Consideration on Stimulational Queen Ant Strategy in Ant Colony Optimization*}

Ichiro Immura $^{\dagger}$, Toshiya ITo $^{\ddagger}$ and Shigeru NAKAYAmA ${ }^{\ddagger}$

\section{1.はじめに}

企業活動における計画・運用に関わる問題の多くは, 最適化問題としてとらえることができる。そのうち， 規模の大きい組合せ最適化問題は, 実用時間で解くこ とが困難であることが知られている。そこで, 近似解 (準最適解) を高速に求める解法の研究が進められてい る。アリの採饂活動をモデル化した最適化手法 (Ant Colony Optimization: ACO) $[1,2]$ は，近時注目を集め ている発見的手法の一つであり, 巡回セールスマン問題 (Traveling Salesman Problem: TSP) やグラフ彩色問 題, 周波数割当て問題などに適用され，その有効性が確認 されている、筆者らは,これまでに, 各アリのフェロモン 追従性に個性を持たせた個性アリ戦略 $\mathrm{AS}_{\text {indi }}[3]$ と, それ を含み女王アリを中心とした社会昆虫であるアリの社会 を模倣した女王アリ戦略 $\mathrm{AS}_{\text {queen }}$ [4] を提案し, TSP のべ ンチマーク問題 TSPLIB に含まれる 51 都市配置の eil51 を用いた実験を通して，その有効性を確認した $[3,4]$.

本研究では, その $\mathrm{AS}_{\text {queen }}$ を, TSPLIBに含まれるさ らに六つの都市配置に適用することによってより詳細に 分析し，さらなる探索性能の向上を図ることを目的とし て, 刺激型女王アリ戦略 $\mathrm{AS}_{\text {queen }}^{S}$ を提案し, 数值実験を 通して最適解発見率と平均反復回数を評価する。

\section{2. 女王アリ戦略 $\mathrm{AS}_{\text {queen }}$ とその探索特性 \\ $2.1 \quad \mathbf{A S}_{\text {queen }}$ の概要}

女王アリ戦略 $\mathrm{AS}_{\text {queen }}$ は, ACOアルゴリズムを用い て解探索を行うワーカ・エージェント（働きアリ）の群れ から成る複数個のグループと, それら複数グループの解

\footnotetext{
* 原稿受付 2005 年 8 月 5 日

$\dagger$ 熊本県立大学 総合管理学部 Faculty of Administration, Prefectural University of Kumamoto; 3-1-100 Tsukide, Kumamoto city, Kumamoto 862-8502, JAPAN

‡鹿児島大学工学部 Faculty of Engineering, Kagoshima University; 1-21-40 Korimoto, Kagoshima city, Kagoshima 890-0065, JAPAN

Key Words: swarm intelligence, Ant Colony Optimization (ACO), Traveling Salesman Problem (TSP).
}

探索状況を監視し，よりよい解の獲得のために各グルー プのフェロモン分布に対して多様化や集中化の処理を施 すクイーン・エージェント（女王アリ）によって構成さ れる. 以下に, $\mathrm{AS}_{\text {queen }}$ の基本的な仕組みを示す。

Step 1 〔初期化〕 それぞれ $n_{\text {ant }}^{(0)}$ 個, $n_{\text {ant }}^{(1)}$ 個, $\cdots, n_{\text {ant }}^{\left(n_{\text {grp }}-1\right)}$ 個のワーカ・エージェントの群れから成る $n_{g r p}$ 個の グループである，グループ $(0)$, グループ $(1), \cdots$, グループ $\left(n_{g r p}-1\right)$ を用意し，それら $n_{g r p}$ 個のグ ループごとに, 初期エージェントを配置して初期 フェロモンを付与する.

Step 2 〔解の探索〕各グループごとに独立して ACO ア ルゴリズムを実行し，一定の反復回数 $I_{c}$ 回ごとに， これまでの最良解 $S^{(g)}(\mathrm{g}$ はグループ番号を表し， 巡回路 $S^{(g)}$ の巡回路長は $L\left(S^{(g)}\right)$ で示す）をクイー ン・エージェントに報告する。

Step 3 [終了判定〕予め指定された探索の終了条件を 満たしていればStep 5へ，なければStep 4へ進む.

Step 4 〔探索状況の評価・改善〕クイーン・エージェン トは, 各グループが前回報告したローカル最良解 $S_{L}^{(g)}$ と, これまでに求められた最も優れたグローバ ル解 $S_{G}$ を保持しており， $I_{C}$ 回ごとに各グループか ら報告される $S^{(g)}$ を評価し, その結果に従って多様 化処理や集中化処理を対象となるグループに施す. その後, Step 2 へ戻る.

Step 5【探索終了〕予め指定された条件を満足したた め，探索を終了する。

今回の実験においては, $\mathrm{AS}_{\text {queen }}$ を構成する $\mathrm{ACO} ア$ ルゴリズムとして, $\mathrm{AS}_{\text {rank }}^{R S}[5]$ を基本として各アリに個 性（異なるランダム選択率）を持たせた個性アリ戦略 $\mathrm{AS}_{\text {indi }}[3]$ を採用するものとした。 なお, 多様化処理や集 中化処理の具体的な内容を含め, $\mathrm{AS}_{\text {queen }}$ の詳細につい ては，筆者らの先行研究 [4] を参照していただきたい.

\section{$2.2 \quad \mathrm{AS}_{\text {queen }}$ の探索特性}

$\mathrm{AS}_{\text {queen }}$ の探索特性を確認するため, 対象問題を増や して数值実験を行った．対象問題および実験で用いたパ ラメー夕值は, Table 1 に示すとおりである.ここで, 
Table 1 Parameter values used in the experiment

\begin{tabular}{|c|c|c|c|c|c|c|c|c|c|c|c|c|c|c|c|}
\hline \multirow{2}{*}{ TSPLIB } & \multirow{2}{*}{$n_{c i t y}$} & \multirow{2}{*}{$S_{\text {opt }}$} & \multicolumn{10}{|c|}{ for $\mathrm{AS}_{\text {indi }}$} & \multicolumn{3}{|c|}{ for $\mathrm{AS}_{\text {queen }}$} \\
\hline & & & $n_{\text {ant }}^{(g)}$ & $\alpha$ & $\beta$ & $\rho$ & $Q$ & $\sigma$ & $r^{\min }$ & $r^{\max }$ & $c l$ & $\tau_{0}$ & $n_{g r p}$ & $I_{c}$ & $n_{\text {init }}$ \\
\hline eil51 & 51 & 426 & 51 & 1 & 5 & 0.5 & 100 & 6 & 0.01 & 0.10 & 9 & $10^{-5}$ & 5 & 30 & 10 \\
\hline $\operatorname{att} 48$ & 48 & 10,628 & 48 & 1 & 5 & 0.5 & 2,494 & 6 & 0.01 & 0.10 & 8 & $10^{-5}$ & 5 & 30 & 9 \\
\hline berlin52 & 52 & 7,542 & 52 & 1 & 5 & 0.5 & 1,770 & 6 & 0.01 & 0.10 & 9 & $10^{-5}$ & 5 & 30 & 10 \\
\hline eil76 & 76 & 538 & 76 & 1 & 5 & 0.5 & 126 & 6 & 0.01 & 0.10 & 13 & $10^{-5}$ & 5 & 30 & 15 \\
\hline pr76 & 76 & 108,159 & 76 & 1 & 5 & 0.5 & 25,389 & 6 & 0.01 & 0.10 & 13 & $10^{-5}$ & 5 & 30 & 15 \\
\hline eil101 & 101 & 629 & 101 & 1 & 5 & 0.5 & 147 & 6 & 0.01 & 0.10 & 18 & $10^{-5}$ & 5 & 30 & 20 \\
\hline $\operatorname{lin} 105$ & 105 & 14,379 & 105 & 1 & 5 & 0.5 & 3,375 & 6 & 0.01 & 0.10 & 19 & $10^{-5}$ & 5 & 30 & 21 \\
\hline
\end{tabular}

$n_{c i t y}$ は問題の規模を表す都市数, $S_{o p t}$ は最適解の巡回 路長である.また， $\mathrm{AS}_{\text {indi }}$ に関するパラメータである， $n_{\text {ant }}^{(g)}$ は 1 グループあたりのワーカ・エージェント数, $\alpha$ と $\beta$ はフェロモンとヒューリステイックな情報のどちら を重要視するかを決定する定数， $\rho$ はフェロモンの蒸発 率を決める定数， $Q$ は分泌するフェロモン量に関係する 定数, $\sigma$ はランク付けに関係する定数, $r^{\min }$ と $r^{\max }$ は ランダム選択率の最小值と最大值， $c l$ は探索の効率化を 図るための候補リストに記録する都市数，そして $\tau_{0}$ は フェロモン量の下限值である.さらに， $\mathrm{AS}_{\text {queen }}$ に関す るパラメータである, $n_{g r p}$ はグループ数, $I_{c}$ はクイー ン・エージェントへの解 $S^{(g)}$ の提出頻度を決める定数, そして $n_{\text {init }}$ は多様化処理における初期化対象都市数で ある。なお，これらのパラメー夕值の決定においては， eil51を対象とした予備実験をもとに決定した。とくに， 都市数に影響されると考えられる $c l$ と $n_{\text {init }}$ については, eil51の都市数に対する比を考慮し, 最適解の巡回路長に 影響されると考えられる $Q$ については, eil51の最適解 の巡回路長に対する比を考慮するものとした. 試行回数 は 20 回とし，各試行における最大反復回数は 10,000 回 として最適解が発見できた時点で探索を終了するものと した. また，時点 $t=0$ における枝 $(i, j)$ の初期フェロモ ン量 $\tau_{i j}(0)$ は $\tau_{i j}(t)$ の下限 $\tau_{0}$ とした.

最適解発見率 ${ }^{1}$ (棒) と平均反復回数 (折れ線) に関す る実験結果を Fig. 1 に示す。この結果より, 都市数が比 較的少ない問題に対してはよい結果が得られているが, 都市数が増えると最適解発見率に低下が見られ, それに 伴い平均反復回数が増加している.この原因を確認する ため, $\mathrm{AS}_{\text {queen }}$ における各グループの解推移を分析した ところ, 探索が進むにつれて, つまり反復回数が増すご とに多様化処理に対する集中化処理の割合が減少傾向に あることがわかった. $\mathrm{AS}_{\text {queen }}$ の集中化処理は, クイー ン・エージェントが保持しているこれまでに求められた 最も優れた解 $S_{G}$ が, ワーカ・エージェント群から成る 各グループ $(g)$ から $I_{c}$ 回ごとに報告のある $S^{(g)}$ のうち最 も優れた解 $S_{L}^{*}$ で更新されたときのみ行われる. その更 新条件は $L\left(S_{L}^{*}\right)<L\left(S_{G}\right)$ が真の場合であるため, 探索が 進むにつれて必然的に集中化処理の実行回数が減少する ことになる，そのため，多様化処理の影響が過剰になり，

\footnotetext{
${ }^{1} 20$ 回試行中 20 回最適解を発見できれば $100 \%$ となる.
}

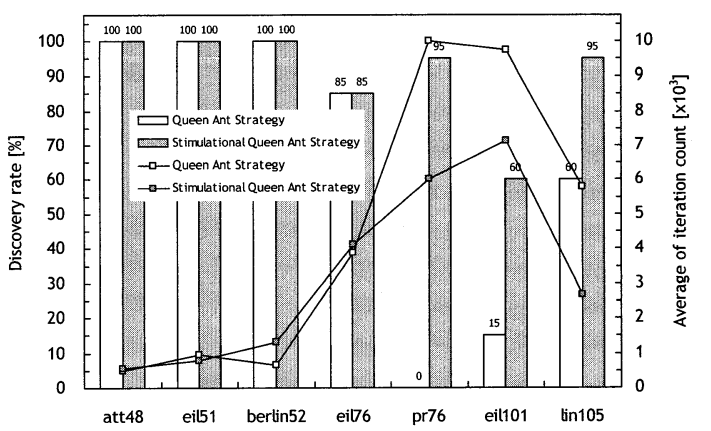

Fig. 1 Experimental results of both discovery rate of optimal solution (Bar) and average of iteration count (Polyline) in "AS queen" and " $\mathrm{AS}_{\text {queen }}^{S}$ "

その結果として最適解を発見しにくい状況になっている と考えられる. att48, eil51, berlin52の都市数が比較 的少ない問題では, この影響があまりなく, 約 3,000回 反復以内で最適解を発見できていた。また, pr76のよう に同じ都市数でも都市配置の違いにより，この過剰な多 様化が大きく影響を及ぼす場合があることもわかった.

\section{3. 刺激型女王アリ戦略 $\mathbf{A S}_{q u e e n}^{S}$ の提案}

\section{1 女王アリによる刺激処理の導入}

前述の問題点を解決するため，ここでは探索が進んだ 段階で集中化処理の減少により起こり得る過剩な多様 化を避けることを目的として, 女王アリによる刺激処理 を新たに導入する.この刺激処理は, $I_{c_{1}}^{S}$ 回反復して探 索が進んだ後, クイーン・エージェントが保持する $S_{G}$ の更新がない期間が $I_{c_{2}}^{S}$ 回続いた場合, つまり反復回数 で表現すると $\left(I_{c} \times I_{c_{2}}^{S}\right)$ 回続いた場合に実行する。具体 的には, 刺激率 $r_{S}$ で選ばれたグループ $(g)$ に属する全 ワーカ・エージェントが持つ巡回路の先頭に, クイーン・ エージェントが保持している巡回路 $S_{G}$ の 1 部分区間を コピーすることで刺激を与え, 集中化処理を誘発させる. この刺激処理により, その近傍を集中的に探索すること が期待されると共に，コピーされた 1 部分区間が探索済 みとなることによる探索空間縮小の効果も期待できる.

なお，この刺激処理のある女王アリ戦略 $\mathrm{AS}_{\text {queen }}$ を, ここでは刺激型女王アリ戦略 $\mathrm{AS}_{\text {queen }}^{S}$ とよぶことにする.

\section{2 刺激型女王アリ戦略 $\mathbf{A S}_{\text {queen }}^{S}$ の仕組み}

$\mathrm{AS}_{\text {queen }}^{S}$ の基本的な仕組みは, $\mathrm{AS}_{\text {queen }}$ とほぼ同じで あるが，その違いは 2.1 節の Step 4 〔探索状況の評価 · 


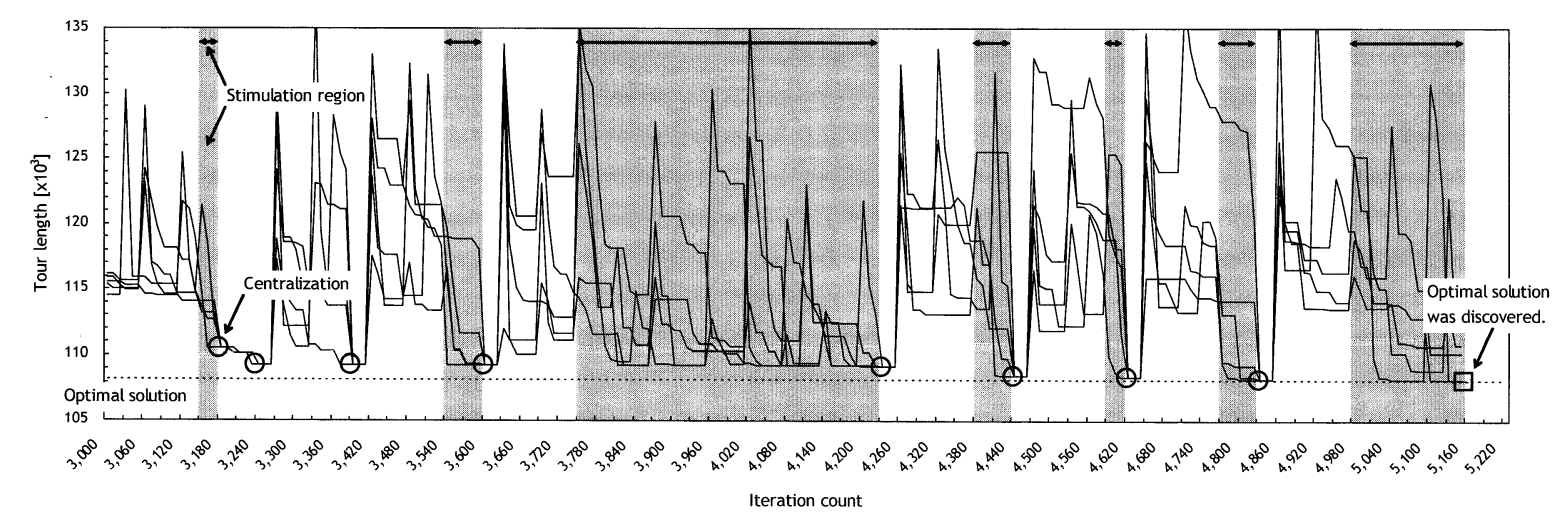

Fig. 2 Transition of $L\left(S^{(g)}\right)$, which is the tour length of $S^{(g)}$ on five groups, in "AS $\mathrm{S}_{\text {queen }}$ " in the case of "pr76"

改善了にあり, $\mathrm{AS}_{\text {queen }}^{S}$ では以下のようになる.

Step 4 〔探索状況の評価・改善〕クイーン・エージェン トは, 各グループが前回報告した最良解 $S_{L}^{(g)}$ と, こ れまでに求められた最も優れた解 $S_{G}$ を保持してお り， $I_{c}$ 回ごとに各グループから報告される $S^{(g)}$ を 評価し，その結果に従って多様化処理や集中化処理 を対象となるグループに施す。つぎに，現時点の反 復回数が $I_{c_{1}}^{S}$ 回を超えており, かつクイーン・エー ジェントが保持している $S_{G}$ の更新がない期間が $I_{c_{2}}^{S}$ 回続いた場合，刺激率 $r_{S}$ で選ばれたグループ $(g)$ に 対して刺激処理を施す。その後, Step 2へ戻る.

\section{4. 刺激型女王アリ戦略 $\mathrm{AS}_{\text {queen }}^{S}$ の評価実験}

\section{1 実験内容}

$\mathrm{AS}_{\text {queen }}^{S}$ の刺激処理の効果を確認するため, 数值実験 を行った. $\mathrm{AS}_{\text {queen }}^{S}$ で新たに導入されたパラメータ值は, $\left(I_{c_{1}}^{S}, I_{c_{2}}^{S}, r_{S}\right)=(3000,5,0.8)$ とし, その他のパラメー夕值 については，2.2 節の実験と同様とした。また，刺激処 理でコピーされる巡回路の 1 部分区間は，その開始遺伝 子座をランダムに決定し，さらに部分区間の長さを 0 か ら【 $\left.n_{\text {city }} \times 3 / 4\right\rfloor$ 都市の範囲でランダムに決定するものと した. 試行回数は 20 回とし, 各試行における最大反復 回数は 10,000 回として最適解が発見できた時点で探索 を終了するものとした。

\section{2 最適解発見率と平均反復回数の評価}

最適解発見率 (棒) と平均反復回数（折れ線）に関す る実験結果を，2.2 節の Fig. 1 に重ねて示す.この結果 から, 都市数の比較的少ない問題に対する探索性能を維 持しつつ, 都市数が比較的多い問題に対して, 最適解発 見率抒よび平均反復回数の観点で改善がなされている ことが確認できる。これは，女王アリによる刺激処理に よって集中化処理が誘発され，過剩な多様化を回避でき たためであると考えられる。

\section{3 新たに導入した刺激処理の効果}

新たに導入した刺激処理による集中化処理の誘発過程 を確認するため, 今回の実験において刺激処理の効果が 最も見られた pr76（最適解の巡回路長は 108,159）に対
する各グループ (5グループ) における解の推移を Fig. 2 に示す. 同図は, 刺激処理が適用されれる $I_{c_{1}}^{S}$ 回反復後 の解推移であり, 図中の○印は集中化処理が行われたこ とを， 口印は最適解が発見されたことを示している。ま た，灰色の領域（左右の矢印で示された領域）は，新た に導入した女王アリによる刺激処理が，その期間で実行 されたことを示している.

この結果を見ると, 反復回数が $I_{c_{1}}^{S}$ 回後では, 灰色領 域の直後に集中化処理を意味する○印が多く存在してお り，刺激処理により集中化処理が誘発されていることが 確認できる. なお, 灰色領域の直後でない○印は, 提案 する刺激処理に誘発された集中化処理ではなく, 従来の $\mathrm{AS}_{\text {queen }}$ の枠組みにより実行されたものである.

\section{5. おわりに}

女王アリ戦略 $\mathrm{AS}_{\text {queen }}$ に刺激処理を導入した刺激型女 王アリ戦略 $\mathrm{AS}_{\text {queen }}^{S}$ の提案により, 従来の $\mathrm{AS}_{\text {queen }}$ に比 べ探索性能を向上させることができた，今後は，新たに 導入した刺激処理を与える時期や頻度に関して, より詳 細に検討していきたいと考えている.

\section{参考文献}

[1] E. Bonabeau, M. Dorigo and G. Theraulaz: Swarm Intelligence - From Natural to Artificial Systems, Oxford University Press (1999)

[2] M. Dorigo, V. Maniezzo and A. Colorni: The ant system: Optimization by a colony of cooperating agents; IEEE Trans. Syst. Man Cybern. B, Vol. 26, No. 1, pp. 1-13 (1996)

[3] 飯村, 松留, 中西, 中山: 巡回セールスマン問題に扔ける ACO による個性アリ戦略の検討 ; 信学論, Vol. J88-D-I, No. 4, pp. 900-905 (2005)

[4] 飯村, 松留, 中山: 群知能 ACOに扔ける女王アリ戦略 の検討 ; 信学論, Vol. J88-D-I, No. 10, pp. 1599-1602 (2005)

[5] 中道, 有田：ACOに打けるランダム選択に基づく多様性 調節の効果; 情処学論, Vol. 43, No. 9, pp. 2939-2947 (2002) 